\title{
Ad solam memoriam oder ut plena fides adhibeatur? Zu notariell beglaubigten \\ Transsumpten aus bayerischen \\ und österreichischen Urkundenbeständen
}

\section{Ad solam memoriam or ut plena fides adhibeatur? Notarized inserts from Bavarian and Austrian charter inventories}

Magdalena Weileder / Magdalena.Weileder@|rz.uni-muenchen.de

Historisches Seminar der LMU München

\begin{abstract}
The study deals with notarized 14th and 15th century copies from Bavarian and Austrian charter inventories. There are some terminological irregularities in the German speaking research literature that cohere with the definition of insert ("Transsumpt"), which cannot be harmonized with the late medieval linguistic usage. Subsequently, the article describes the different forms of notarized charter copies and tries to point out if they were sustainable according to roman and canonical process law.
\end{abstract}

\section{Keywords}

Transsumpt, vidimus, notarization, copy, late middle ages, notary, notary's charters, notary's instruments, credibility, evidence. 
Obwohl Abschriften in der diplomatischen Forschung oft nur als subsidiäre Überlieferungsform der zugrundeliegenden Urkundenoriginale wahrgenommen werden, vermitteln sie mehr als den Wortlaut ihrer Vorlage. Sie sind zum einen ein Beleg dafür, dass jemand die jeweilige Urschrift kannte und für wichtig genug erachtete, sie abzuschreiben. Zum anderen geben sie je nach Überlieferungskontext, Entstehungsumständen und Form sowie dem daraus ableitbaren Zweck Anhaltspunkte für die Bedeutung des abgeschriebenen Schriftstücks, und zwar sowohl im Hinblick auf den Stellenwert schriftlicher Aufzeichnungen im Allgemeinen, als auch für das „Nachleben“ des Einzelstücks. Die Abschrift einer Urkunde liefert Hinweise darauf, wie diese Urkunde genutzt und bewertet wurde: Abschriften in Kopialbüchern oder formlose Kopien auf Papier dienten vor allem der internen Verwaltung. In Formelbüchern werden Urkunden dagegen abgeschrieben, weil man sie formal für besonders typisch oder aber außergewöhnlich, jedenfalls nützlich hielt. In Familienchroniken wiederum sind Urkundenabschriften zu anderen Zwecken enthalten als in Gerichtsakten. Entsprechend unterschiedliche Rückschlüsse kann man auf die Bewertung einer Urkunde zum Zeitpunkt ihrer Abschrift ziehen: ob sie noch rechtlich relevant war, vielleicht sogar in einem Gerichtsprozess zu Beweiszwecken benötigt wurde, oder ob man sie eher als Zeugnis für die historische Bedeutung der eigenen Institution oder Familie wertschätzte, bzw. - im Hinblick auf das übergeordnete Thema dieses Tagungsbandes - wo die Urkunde zu verorten ist „zwischen Recht und Erinnerung“.

Um stichhaltige Argumente aus der Form einer Abschrift abzuleiten, muss man jedoch auch die zeitgenössischen Gebräuche berücksichtigen, um das Gewöhnliche vom Besonderen unterscheiden und entsprechend gewichten zu können. Im Folgenden soll daher exemplarisch eine bestimmte Form der kopialen Urkundenüberlieferung herausgegriffen und anhand von Beispielen bis zum Jahr 1500 aus ausgewählten Urkundenbeständen bayerischer und österreichischer Archive ${ }^{1}$ untersucht werden: die notariell beglaubigten Abschriften², die ja nicht nur Abschriften, sondern zugleich eigenständige

1 Quellengrundlage der vorliegende Studie sind 289 notariell beglaubigte Abschriften aus dem 14 . und 15. Jahrhundert aus den folgenden, auf www.monasterium.net (15. 05. 2017) digitalisierten Archivbeständen: Bayerisches Hauptstaatsarchiv (= BayHStA) München: Domkapitel Passau Urkunden, Hochstift Passau Urkunden, Domkapitel Salzburg Urkunden, Erzstift Salzburg Urkunden, sowie die Urkundenbestände der Klöster Aldersbach, Altenhohenau, Altomünster, Asbach, Formbach, Fürstenzell, Neuburg an der Donau, Niederaltaich, Passau-Niedernburg, Passau-St. Nikola, Raitenhaslach, Ranshofen, St. Salvator, Vilshofen, Windberg, des Münchner Angerklosters und des Chorstifts Altötting; Haus-, Hof und Staatsarchiv (= HHStA) Wien: Urkunden des Erzstifts und des Domkapitels von Salzburg aus der Allgemeine Urkundenreihe (= AUR); Archiv der Erzdiözese Salzburg (= AES): Urkunden.

2 Aus der Vielzahl der Veröffentlichungen zum mittelalterlichen Notariat nördlich der Alpen: Koechling, Ludwig: Untersuchungen über die Anfänge des öffentlichen Notariats in Deutschland. Marburger Studien zur älteren deutschen Geschichte 2/1. Marburg an der Lahn 1925; Luschek, Fritz: Notariatsurkunde und Notariat in Schlesien von den Anfängen (1282) bis zum Ende des 16. Jahrhunderts. Hg. von L. Santifaller. Historisch-Diplomatische Forschungen 5. Weimar 1940; Schuler, Peter-Johannes: Geschichte des Südwestdeutschen Notariats. Von seinen Anfängen bis zur Reichsnotariatsordnung von 1512. Veröffentlichungen des Alemannischen Instituts Freiburg i. Br. 39. Bühl (Baden) 1976; Hlaváček, Ivan: Das öffentliche Notariat in den böhmischen Ländern von den Anfängen bis zu der hussitischen Revolution. In: Notariado público y documento privado: de los orígenes al siglo XIV. Actas del VII Congresa Internacional de Diplomática. Band II. Valencia 1986, S. 1177-1194; Neschwara, Christian: Geschichte des österreichischen Notariats. Band I: Vom Spätmittel- 
Urkunden mit erkennbarem Aussteller und eigener Datierung sind. Indem der Notar durch seine Beglaubigung eine gewisse Verantwortung für diese Abschrift übernimmt, erhebt sie, anders als formlose Kopien, einen Anspruch auf Glaubwürdigkeit auch gegenüber Dritten. Es soll daher insbesondere auf die Frage eingegangen werden, wie beweiskräftig notariell beglaubigte Abschriften waren.

Um Missverständnisse zu vermeiden, sei vorab noch auf terminologische Unstimmigkeiten hingewiesen, die in der deutschsprachigen Forschungsliteratur festzustellen sind. Hier werden notariell beglaubigte Abschriften aus dem Mittelalter meist als „Vidimus“ oder „Transsumpt“ bezeichnet. Die etymologische Herkunft der Begriffe von der Verbform vidimus (wir haben gesehen) und transsumere (übertragen) ist unstrittig, doch was genau darunter zu verstehen ist, wird sehr unterschiedlich und zum Teil widersprüchlich beantwortet. ${ }^{3}$ Die Definition von "Vidimus“ erscheint dabei noch relativ unproblematisch, solange vor allem auf formale Kriterien abgestellt wird (eine Urkunde, in der der Aussteller erklärt, eine andere, im Wortlaut wiedergegebene Urkunde gesehen zu haben und oft außerdem bestätigt, dass diese unbeschädigt gewesen sei). ${ }^{4}$ Das Verständnis von "Transsumpt“ ist dagegen sehr uneinheitlich, je nachdem, ob man sich am Sprachgebrauch in den Quellen oder an Definitionen in der deutschsprachigen Einführungsliteratur orientiert. Diese Widersprüche sind bislang kaum beachtet worden, ${ }^{5}$ so dass oft nur aus dem Kontext zu erschließen ist, was ein einzelner Autor mit „Transsumpt“ meint.

Eine der gängigsten Definitionen ist die im „Werkzeug des Historikers“ von Ahasver von Brandt, dem in Deutschland meistverkauften Einführungswerk zu den Historischen Hilfswissenschaften. Er beschreibt Transsumpt und Vidimus als zwei „im Rechtszweck“

alter bis zum Erlaß der Notariatsordnung 1850. Wien 1996; Nuhlíček, Josef: Veřejní notáři v českých městech, zvláště v městech pražských až do husitské revoluce. Hg. von Ivan Hlaváček - Markéta Marková. Praha 2011; Weileder, Magdalena: Spätmittelaltelriche Notarsurkunden. Prokurationen, beglaubigte Abschriften und Delegatenurkkunden aus bayerischen und österreichischen Baständen. Archiv für Diploamtik Beiheft 18. Köln - Weimar - Wien 2019.

3 Vgl. z. B. die sehr unterschiedlichen Definitionen bei Spiegel, Joachim: Art. Vidimus. Lexikon des Mittelalters (= LexMA) 8. 1997, Sp. 1636f. und Art. Transsumpt. LexMA 8. 1997 Sp. 952f.; Hartmann, Josef: Urkunden. In: Die archivalischen Quellen. Mit einer Einführung in die Historischen Hilfswissenschaften. 5. erweiterte und aktualisierte Auflage. Hg. von Friedrich Beck und Eckard Henning. Köln - Weimar Wien 2012, S. 25-54, hier: S. 43; und Rohr, Christian: Historische Hilfswissenschaften. Eine Einführung. Wien - Köln - Weimar 2015, S. 41, sowie die unten thematisierte Definition von Ahasver von Brandt.

4 Vgl. Spiegel, J.: Vidimus, Sp. 1636f. Problematisch scheinen Festlegungen auf einen bestimmten Zweck oder ein bestimmtes Verhältnis des Vidimierenden zum Rechtsinhalt der vidimierten Urkunde, da ein Vidimus nicht immer als Vervielfältigung durch einen neutralen Dritten (so z. B. definiert bei Spiegel, J.: Vidimus; Brandt, Ahasver von: Werkzeug des Historikers. Eine Einführung in die Historischen Hilfswissenschaften. Stuttgart $2012^{18}$, S. 96), sondern in manchen Fällen als Konsenserklärung oder Sichtvermerk eines Betroffenen verstanden werden muss, vgl. unten Anm. 11.

5 Auf diese Unstimmigkeiten haben bislang, soweit ersichtlich, allein Bruchmann, Karl: Beschreibung von Kaiser- und Königssiegeln in Transsumpten. Blätter für deutsche Landesgeschichte 91, 1954, S. 277-293, hier: S. 278 Anm. 2 sowie Gussone, Monika: Rezension zu Vogtherr, Thomas: Urkundenlehre. Basiswissen, Hannover 2008. H-Soz-Kult 07. 10. 2009: www.hsozkult.de/publicationreview/id/rezbuecher-12677 (15. 5. 2017), hingewiesen. 
verschiedene Arten von beglaubigten Abschriften und bestimmt als Abgrenzungskriterium die Verantwortung des Ausstellers für die abgeschriebene Urkunde: Ein Transsumpt werde vom Aussteller des Originals selbst oder von dessen Rechtsnachfolger ausgestellt und beinhalte stets auch die Bestätigung der im Insert verliehenen Rechte. Dagegen sei der Aussteller eines Vidimus „persönlich uninteressiert“ und bestätige nur, die ältere Urkunde gesehen zu haben sowie die korrekte Wiedergabe ihres Textes, übernehme aber keine Verantwortung für den rechtlichen Inhalt. Dementsprechend rechnet Ahasver von Brandt die durch öffentliche Notare beglaubigten Abschriften ausdrücklich und grundsätzlich den Vidimus-Urkunden zu. ${ }^{6}$ - Brandts Definition von „Transsumpt“ lässt sich mit der spätmittelalterlichen Urkundensprache allerdings nicht in Einklang bringen. Einerseits werden notariell beglaubigte Abschriften von den Notaren selbst als transsumpta bezeichnet: Spätestens seit der Mitte des 14. Jahrhunderts ${ }^{7}$ sind in entsprechenden Urkunden (und auf deren Rückseiten) ganz regelmäßig die Worte transsumi, transsumptum oder eine verwandte Form zu finden. ${ }^{8}$ Andererseits sucht man diese Ausdrücke im Zusammenhang mit jenen Urkunden, die Brandt als „Transsumpte“ bezeichnet, vergebens. Statt transsumere sind für die Bestätigung des Rechtsinhalts inserierter Urkunden durch den Nachfolger Verben wie innovare, approbare, ratificare oder confirmare üblich. ${ }^{9}$ Außerdem ist durchaus kein grundsätzlicher Unterschied zwischen „Transsumpt“ und „Vidimus“ auszumachen: nicht selten wird eine Urkunde als transsumptum seu vidimus bezeichnet. ${ }^{10}$ Der erste Begriff scheint dabei der engere zu sein, der vor allem oder sogar

6 Brandt, A. v.: Werkzeug, S. 96f.

7 Im 13. und frühen 14. Jahrhundert scheint noch die Bezeichnung exemplum zu überwiegen, vgl. Härtel, Reinhard: Notarielle und kirchliche Urkunden im frühen und hohen Mittelalter. Historische Hilfswissenschaften 4. Wien - München 2011, S. 29f.; Hageneder, Othmar: Original, Kopie, Ausfertigung. Beiträge zur Terminologie und Glaubwürdigkeit mittelalterlicher Urkunden. In: Vielfalt und Aktualität des Mittelalters. Festschrift für Wolfgang Petke zum 65. Geburtstag. Hg. von Sabine Arend - Daniel Berger. Bielefeld 2007, S. 559-573, hier: S. 565-568.

8 Z. B. HHStA Wien, AUR 1343 September 18: litteram [...] fideliter transsumsi; BayHStA München, Domkapitel Passau Urk. 1066 (1431 März 3): ipsas litteras transsumi [...] mandavimus; AES, Urk. 2776 (1454 März 16): quasdam litteras [...] ad transsumendum [...] exhiberi fecit; BayHStA München, Domkapitel Passau Urk. 1344 (1476 Juli 31): huiusmodi transsumpto publico.

9 In den Bänden der Monumenta Germaniae Historica (= MGH) Diplomata (= DD) und Constitutiones (= Const.) ist der Begriff transsumptum erst im 14. Jahrhundert und dann wiederum nur für (notariell) beglaubigte Abschriften nachgewiesen, obwohl durchaus zahlreiche Konfirmationsurkunden abgedruckt sind, denen der Wortlaut der jeweils bestätigten Urkunde inseriert ist, z. B. MGH DD XIV-2. Friderici II. diplomata. Ed. W. Koch. Hannoverae 2007, S. 367-369 Nr. 357, MGH DD XVIII-1. Heinrici Rasponis et Wilhelmi de Hollandia diplomata. Hg. von D. Hägermann - J. G. Krushieer unter Mitwirkung von A. Gawlik. Hannoverae 1989, S. 158-161 Nr. 117; MGH Const. V. Hannoverae - Lipsiae 1909-1913, S. 140f. Nr. 144. Zu confirmare/approbare/ratificare/innovare als Verben der Bestätigung und Zustimmung in Passauer Bischofsurkunden vgl. Epping, Claudia: Kanzlei- und Urkundenwesen der Passauer Bischöfe im Spätmittelalter. Ausgewählte Urkunden Bischof Wernhards von Prambach (1286-1313). Ostbairische Grenzmarken 40, 1998, S. 49-74, hier: S. 51f.

10 Z. B. BayHStA München, Kloster Fürstenzell Urk. 526 (1434 Juli 5): vnum vidimus seu transsumptum; ebd., Kloster Alderbach Urk. 795 (1438 Dezember 17): huiusmodi publico instrumento, vidimus seu transsumpto appellato; ebd., Kloster Altomünster Urk. 172 (1488 September 15): transsumptum, exemplum sew vidimus; die drei Ausfertigungen von HHStA Wien, AUR 1427 II 16 werden rückseitig jeweils als vidimus bezeichnet, im Urkundentext und in den notariellen Unterschriften liest man dagegen transsumpto bzw. transsumpsi und transsumptum. 
ausschließlich für notariell beglaubigte Abschriften gebräuchlich war, während als „Vidimus" auch beglaubigte Abschriften in Form von Siegelurkunden bezeichnet werden, an denen kein öffentlicher Notar beteiligt war. ${ }^{11}$

Da nicht ersichtlich ist, worauf die Definitionen im „Werkzeug des Historikers“ gründen, kann man nur die Vermutung anstellen, dass sie auf einer missverstandenen Passage zum „Transsumpt“ in älteren diplomatischen Überblickswerken beruhen. ${ }^{12}$ Dass auch in der jüngeren Literatur oft die Verknüpfung des Begriffes „Transsumpt“ mit einem bestimmten Verhältnis zwischen den Ausstellern von Ur- und Abschrift beibehalten wird, ${ }^{13}$ ist wohl vor allem einem Bedürfnis nach klarer begrifflicher Abgrenzung zum Vidimus geschuldet. - Im Folgenden aber wird der Begriff „Transsumpt“ dem nach bisherigen Erkenntnissen recht konsequenten spätmittelalterlichen Sprachgebrauch entsprechend nicht für Bestätigungen von Vorgängerurkunden, sondern für Abschriften verwendet, bei denen der Wortlaut der Vorlage in eine Rahmenurkunde eingerückt ist, durch die diese Abschrift beglaubigt wird und die in der Regel von einem öffentlichen Notar ausgefertigt ist.

Transsumpte sind wahrscheinlich die am häufigsten erhaltenen Notarsurkunden im nordalpinen Reich, ${ }^{14}$ wobei hier unter „Notarsurkunden“ all jene Urkunden gefasst

11 Z. B. Vidimus des Freisinger Propstes Ulrich für einen Freisinger Domherren im BayHStA München, Chorstift Altötting Urk. 414 (1439 Juni 24) und Vidimus des Bürgermeisters und Rats von Landshut für Pangraz Thumperger und dessen Ehefrau ebd., Hochstift Passau Urk. 2483 (1488 August 18), beide auf der Rückseite als vidimus bezeichnet; in einer Urkunde des Rats von Burghausen ebd., Kloster Raitenhaslach Urk. 1449 IX 7 tritt als Petent der Abt von Raitenhaslach auf und bittet um ain abgeschrifft vnd vidimus. - Diese drei Beispiele sind auf Deutsch verfasst. Stichproben in einzelnen Beständen vermittelten den Eindruck, dass dies auf fast alle nicht-notariellen Vidimusurkunden zutrifft, diese eher weltliche Angelegenheiten betreffen und der Vidimierende oft nicht neutraler Dritter war, sondern durch die Vidimierung die Kenntnisnahme einer ihn betreffenden Urkunde bestätigte. Ob diese Eindrücke zutreffen, müsste jedoch noch an umfangreicherem Material untersucht werden.

12 Der Ursprung von A. von Brandts Definition ist nicht direkt zu erschließen, da eine konkrete Quelle nicht genannt wird. Vermutlich lässt sie sich auf eine Passage bei Ficker, Julius: Beiträge zur Urkundenlehre. Bd. 1. Innsbruck 1877, zurückführen, die fast wörtlich auch bei Leist, Friedrich: Urkundenlehre. Katechismus der Diplomatik, Paläographie, Chronologie und Sphragistik. Leipzig 1882, S. 58 und Posse, Otto: Die Lehre von den Privaturkunden. Leipzig 1887, S. 79f. zu finden ist. So schreibt Ficker, J.: Beiträge S. 272: „Wenn man [eine fälschungsverdächtige Neuausfertigung nicht selbst vornehmen] wollte oder konnte, lag es am nächsten, sich an den Rechtsnachfolger des früheren Ausstellers um eine Neuausfertigung zu wenden. Daraus hat sich später die Form der Transsumierung, der wörtlichen Einrückung, entwickelt, indem der Rechtsnachfolger die wörtlich wiederholte ältere Urkunde in eine eigene Urkunde einschob, durch welche er für die Neuausfertigung derselben einstand und in der Regel zugleich ihren Inhalt bestätigte.“ Der Ausdruck „Transsumierung“ ist hier rein formal im Sinne von „wörtliche Einrückung“ gebraucht, die Stelle könnte aber so missverstanden worden sein, dass ein Transsumpt grundsätzlich durch den Rechtsnachfolger ausgestellt sein müsse.

13 Vgl. z. B. Schneidmüller, Bernd: Art. Vidimus. Handwörterbuch zur deutschen Rechtsgeschichte $(=\mathrm{HRG})^{1}$ 5, 1998, Sp. 907-909; Kümper, Hiram: Materialwissenschaft Mediävistik. Eine Einführung in die Historischen Hilfswissenschaften. Paderborn 2014, S. 110f. - Auch Härtel, R.: Notarielle und kirchliche Urkunden, S. 29f. übernimmt die Unterscheidung von Transsumpt und Vidimus nach Verantwortung des Ausstellers, stellt ihnen jedoch die notariell beglaubigte Abschrift (exemplum) als dritten Typ gegenüber.

14 In den dieser Studie zugrunde gelegten Archivbeständen machen beglaubigte Abschriften mit 289 von ca. 960 fast ein Drittel aller vor 1500 ausgestellten Notarsurkunden aus. Auch in anderen regional ausgerichteten Studien zum mittelalterlichen Notariat wird die Beglaubigung von Abschriften als eine der 
werden, die von einem öffentlichen, vom Papst und/oder Kaiser direkt oder indirekt autorisierten Notar in publicam formam ausgestellt und mit Signet und Unterschrift versehen sind. Dies schließt neben unbesiegelten, aus der Sicht des Notars formulierten Notariatsinstrumenten auch besiegelte Notarsurkunden ein, die in der deutschsprachigen Forschung oft als „Mischformen von Notariatsinstrument und Siegelurkunde“ bezeichnet werden. Besonders häufig sind notariell beglaubigte Siegelurkunden, die aus der Sicht der siegelnden Person - meist ein Bischof, Abt, Dekan oder anderer höherer Geistlicher - formuliert sind, aber auch alle für ein Notariatsinstrument notwendigen Formularbestandteile wie eine ausführliche Datierung oder eine bestimmte Zeugenformel enthalten. Das Formular dieser besiegelten Notarsurkunden ist weitgehend unabhängig vom jeweiligen Aussteller und erscheint stattdessen ebenso regelmäßig und standardisiert wie das der unbesiegelten Notariatsinstrumente, denen sie in ihrer Häufigkeit generell kaum nachstehen ${ }^{15}$. Speziell die notariell beglaubigten Abschriften sind sogar weit überwiegend in der Form der notariell beglaubigten Siegelurkunde ausgestellt: In den hier berücksichtigten Archivbeständen trifft dies für fast vier Fünftel der notariellen Transsumpte $\mathrm{zu}^{16}$.

Unabhängig davon, ob es sich um ein Notariatsinstrument oder eine notarielle Siegelurkunde handelt, wird in den notariell beglaubigten Abschriften in der Regel folgender Ablauf beschrieben: Vor Aussteller und/oder dem Notar sowie Zeugen erscheint ein Petent, legt eine Urkunde vor, die mehr oder weniger ausführlicher beschrieben wird ${ }^{17}$, und bittet um deren Abschrift. Nachdem der Aussteller sich durch eigene Anschauung von der Unversehrtheit und Unverdächtigkeit dieser Urkunde - die regelmäßig durch eine stereoptype Formel betont wird (z. B. non viciatam, non cancellatam - nec in aliqua sui parte suspectam, sed omni suspicionis vicio prorsus carentem $)^{18}$ - überzeugt hat, wird die Abschrift angefertigt, oft noch mit dem Original abgeglichen und die Übereinstimmung bestätigt ${ }^{19}$.

zentralen Aufgaben öffentlicher Notare genannt, vgl. z. B. Luschek, F.: Notariatsurkunde, S. 33, 104-111; Lönnecker, Harald: Das Notariat in Hessen. Dargestellt nach den Quellen im Hessischen Staatsarchiv zu Marburg. Bd. 1. Marburg an der Lahn 1988, S. 33; Kos, Dušan: Zur Problematik des öffentlichen Notariats in Krain im Mittelalter. Mitteilungen des Instituts für Österreichische Geschichtsforschung 116, 1997, S. 57-73, hier: S. 71.

$15 \mathrm{Zu}$ den verschiedenen Formen von Notarsurkunden einschließlich der sogenannten „Mischformen“ vgl. Schuler, P.-J.: Geschichte, S. 210-219; zum Forschungsstand und zur Bewertung besiegelter Notarsurkunden als „Übergangsformen“ vgl. Fees, Irmgard - Weileder, Magdalena: Spätmittelalterliche Notarsurkunden im Fuldaer Urkundenbestand. In: Das Kloster Fulda und seine Urkunden. Moderne archivische ErschlieBung und ihre Perspektiven für die historische Forschung. Hg. von S. Zwies. Fuldaer Studien 19. Freiburg 2014, S. 144-164, hier: S. 149-153. - Notariatsinstrumente mit fremden Beisiegel sind in den untersuchten Beständen und speziell unter den beglaubigten Abschriften relativ selten und bleiben hier daher ausgeklammert.

16 Von den insgesamt 289 notariell beglaubigten Transsumpten aus den in Anm. 1 aufgeführten Urkundenbeständen sind 226 (ca. 78\%) in der Form der notariellen Siegelurkunde, 44 (ca. 15\%) als unbesiegelte Notariatsinstrumente ausgefertigt und 19 (ca. 7\%) als Notariatsinstrumente mit fremden Beisiegel ausgefertigt. Die meisten Transsumpte (262) stammen aus dem 15. Jahrhundert.

17 Zu unterschiedlich ausführlichen Siegelbeschreibungen in Transsumpten vgl. Bruchmann, K.: Beschreibung.

18 Zitat aus: BayHStA München, Kloster Aldersbach Urk. 484 (1347 September 14).

19 Zum Formular notariell beglaubigter Abschriften vgl. auch Luschek, F.: Notariatsurkunde, S. 104-111. Ein 
In einem Teil der besiegelten Transsumpte wird allerdings zusätzlich noch ein der Transsumierung vorausgegangenes Verfahren beschrieben, das an die schon für das Frühmittelalter belegten sogenannten „Scheinprozesse“ erinnert, als deren Zweck man die Anfertigung glaubwürdiger Abschriften vermutet ${ }^{20}$. Der Aussteller ist bei diesen Transsumpten in der Regel ein ordentlicher oder delegierter Richter, auch wenn die Amtsbezeichnungen unterschiedlich und nicht immer eindeutig mit richterlichen Kompetenzen verknüpft sind ${ }^{21}$. Die Anfertigung der Abschrift folgt erst, nachdem eine förmliche Ladung an Personen erlassen wurde, die von der Angelegenheit betroffen sein oder vernünftige Gründe gegen die Transsumierung vorzubringen haben könnten. So heißt es beispielsweise in einem Transsumpt dreier Papsturkunden auf Bitten des Abtes von Aldersbach, dass der Dekan Valentin von Passau befohlen habe, möglicherweise betroffene Personen, insbesondere aus der Stadt Passau, durch ein an die Tür des dortigen Doms geheftetes Schreiben vorladen zu lassen: Per hoc presens scriptum cunctis id intuentibus pateat evidenter, quod nos [...] omnes et singulos sua communiter vel divisim interesse putantes et quos infrascriptum tangit negocium seu tangere poterit quomodolibet in futurum eorumque procuratores, si qui sint in ciuitate Pataviensis aut extra, ad videndum et audiendum nonnullas litteras apostolicas iura et priuilegia dicti monasterii in se continentes infrascriptorum tenorum produci et per nos recepi, et postquam producte et recepte fuerint, easdem transsumi, exemplari, publicari et in publicam formam redigi mandari, auctoritatemque et decretum ut eidem transsumpti publico in iudicio et extra tanta fides quanta ipsis litteris originalibus adhiberetur interponi, vel dicendum et allegandum causas si quas habeant racionabiles cur id fieri non deberet, per nostras certi tenoris litteras valvis seu portis ecclesie sancti Stephani prothomartiris Pataviensis ad instar edictorum publicorum affigendas et inibi debite exequendas citari mandavimus et fecimus ad diem et horam infrascriptis. ${ }^{22}$

In keinem der Beispiele, die sich in den hier berücksichtigten Archivbeständen erhalten haben, wird tatsächlich auch vom Erscheinen einer Gegenpartei berichtet, dagegen bringt der Petent gelegentlich Zeugen bei, die zu der abzuschreibenden Urkunde und vor allem deren Siegel befragt werden. Erst nachdem sich der Aussteller auf diese Weise von deren Glaubwürdigkeit überzeugt hat, erteilt er dem öffentlichen Notar den

Beispiel für ein durch mehrere Notare unterfertigtes Transsumpt ist abgedruckt bei Nuhliček, J.: Veřejní notárí, S. 123-130 (A 2).

20 Vgl. Bresslau, Harry: Handbuch der Urkundenlehre für Deutschland und Italien. Erster Band. Berlin 19694, S. 90. Zum umstrittenen Begriff des „Scheinprozesses“ vgl. Weitzel, Jürgen: Diplomatik und Rechtsgeschichte. Archiv für Diplomatik (= AfD) 52, 2006, S. 297-312, bes. S. 307-211; Stieldorf, Andrea: Zum „Verschwinden" der herrscherlichen Placita am Beginn des 9. Jahrhunderts. AfD 53, 2007, S. 1-26. S. 2f. Anm. 6; Murray, Alexander Callander: So-called Ficticious Trial in the Merovingian Placita. In: Gallien in Spätantike und Frühmittelalter. Kulturgeschichte einer Region. Hg. von S. Diefenbach - G. M. Müller. Berlin - Boston 2013, S. 297-327.

21 In den bayerischen Diözesen wurde die bischöfliche Gerichtsbarkeit im 14. und 15. Jahrhundert oft nicht von einem Offizial ausgeübt, sondern von Archidiakonen, Domdekanen, Dompröpsten oder sogar Äbten, vgl. Schwab, Christian: Geistliche Gerichtsbarkeit. Historisches Lexikon Bayerns. publiziert am 30. 9. 2011: http://www.historisches-lexikon-bayerns.de/Lexikon/Geistliche Gerichtsbarkeit (15. 5. 2017); Hageneder, Othmar: Die geistliche Gerichtsbarkeit in Ober- und Niederösterreich. Von den Anfängen bis zum Beginn des 15. Jahrhunderts. Forschungen zur Geschichte Oberösterreichs 10. Graz - Wien - Köln 1967.

BayHStA München, Kloster Aldersbach Urk. 1073 (1475 September 15). 
Auftrag zur Transsumierung. In den untersuchten Urkundenbeständen ist dieses Verfahren 42-mal belegt, erstmals im Jahr 1432. Bis 1500 sind dann aus jedem Jahrzehnt Beispiele erhalten. Die anderen beiden Arten von notariell beglaubigten Transsumpten werden hierdurch jedoch nicht verdrängt.

Kaiserlich und päpstlich autorisierte Notare beglaubigten unterschiedslos Papsturkunden, Königs- und Kaiserurkunden, Urkunden von Herzögen, Bischöfen oder Klöstern, und auch der Status der Personen, die als Aussteller besiegelter Transsumpte auftreten, scheint vom Aussteller der jeweils inserierten Urkunde unabhängig. ${ }^{23}$ Auch hinsichtlich des Alters der abzuschreibenden Urkunden gab es offenbar keine Beschränkungen: Es reicht von wenigen Tagen bis zu mehreren Jahrhunderten. ${ }^{24}$ Sehr oft war das abgeschriebene Stück zum Zeitpunkt der Transsumierung bereits über 70 Jahre alt, so dass man davon ausgehen kann, dass die in ihm genannten Zeugen längst verstorben waren, also für eine Bestätigung des Rechtsinhalts im Falle eines Gerichtsprozesses nicht mehr zur Verfügung standen.

Inhaltlich sind die Abschriften vielfältig, wenig überraschend stellten sie jedoch in der Regel Begünstigungen für den Empfänger dar, der deshalb ein Interesse an der Bewahrung des Originals und somit der Transsumierung hatte. Zudem gilt für die Transsumpte, wie generell für Notarsurkunden, dass sie vor allem von Geistlichen in Auftrag gegeben wurden, wobei dieser Befund hier durch die Beständeauswahl noch verstärkt wird. ${ }^{25}$ Relativ häufig handelt es sich um Maut- oder Zollprivilegien; so ließen etwa die Klöster St. Nikola, Fürstenzell, Niederaltaich, Aldersbach und Ranshofen entsprechende königliche oder gräfliche Mautprivilegien notariell transsumieren. ${ }^{26}$ Man kann sich gut vorstellen, dass die Transsumpte dann z. B. mit den Salz- und Weinlieferungen auf Donau und Salzach mitgeführt und den Zollbeamten vorgelegt wurden; schließlich

23 Die einschränkende Bemerkung aus dem Baumgartenberger Formelbuch: Si autem litera imperatoris vel regis transcribenda est, oportet quod scribatur sub sigillis episcoporum vel ducum marchionum vel comitum, quia inferioribus personis vix adhiberetur fides, vt prelatis ecclesiasticis vel ministerialibus (Ed. Rockinger, Ludwig: Briefsteller und Formelbücher des eilften bis vierzehnten Jahrhunderts. Band 2. München 1864, S. 715-838, hier S. 771; vgl. dazu auch Goez, Elke: Pragmatische Schriftlichkeit und Archivpflege der Zisterzienser. Ordenszentralismus und regionale Vielfalt, namentlich in Franken und Altbayern (1098-1525). Münster - Hamburg - London 2003, S. 211) lässt sich für notariell beglaubigte Abschriften nicht bestätigen.

24 Nur zwei Tage liegen zwischen der Ausstellung des Originals und dem Transsumpt bei HHStA Wien, AUR 1395 I 25 und 1442 V 20, 563 Jahre sind es bei BayHStA München, Kloster Ranshofen Urk. 1461 I $21 / 1$.

25 Transsumpte wurden offenbar vor allem für den Eigengebrauch erworben, da sie meistens im Bestand des Petenten überliefert sind. Daraus ergibt sich aus der Auswahl von Urkundenbeständen geistlicher Institutionen zwangsläufig, dass als Empfänger fast ausschließlich Geistliche auftreten. Es gilt jedoch auch grundsätzlich, dass das Notariat im nordalpinen Reich im Zuge der Rezeption des römisch-kanonischen Prozessrechts zunächst vor allem im Bereich der geistlichen Gerichtsbarkeit Eingang fand und erst im Laufe des 15. Jahrhundert in zunehmendem Maße auch im weltlichen Bereich üblich wurde, vgl. Neschwara, Christian: Art. Notar, Notariat. HRG² (HRGdigital): https://www.hrgdigital.de/HRG.notar_notariat (15. 5. 2017).

26 Z. B. BayHStA München, Kloster Fürstenzell Urk. 547 (1439 August 21); Kloster Passau-St. Nikola Urk. 1453 VIII 1; Kloster Ranshofen Urk. 1461 XII 21; Kloster Niederaltaich Urk. 1070 (1494 Juli 11). 
wird die Bitte um Transsumierung oft damit begründet, dass man Beschädigungen des Originals durch Transport oder auch Wasserschäden befürchte. ${ }^{27}$

Die meisten der besiegelten, aber auch einige der unbesiegelten notariellen Transsumpte enthalten den Hinweis, dass dieser Abschrift wie dem Original volle Glaubwürdigkeit zukommen solle (quod huiusmodi transsumpto tamquam originalibus ubicumque locorum stetur credatur et adhibeatur plena fides $^{28}$ ). Dennoch ist nicht davon auszugehen, dass eine notariell beglaubigte Abschrift grundsätzlich als gleichwertiger Ersatz der Vorlage galt. Entgegen Harry Bresslaus Einschätzung (1889), wonach es „Zweifellos und allgemein bekannt [sei], daß man [...] den von einem öffentlichen Notar hergestellten Abschriften dieselbe Beweiskraft wie den Originalen" beigemessen habe, ${ }^{29}$ haben dies schon Ferdinand Oesterley (1842), Winfried Trusen (1977) und Petra Schulte (2003) unter Heranziehung päpstlicher Dekretalen und des Speculum iudiciale von Guilelmus Durantis gezeigt. ${ }^{30}$ Nach römisch-kanonischem Prozessrecht sind durchaus nicht alle notariellen Transsumpte voll - also auch ohne Hinzuziehung weiterer Urkunden oder Zeugen - beweiskräftig. ${ }^{31}$

Die maßgebliche Dekretale im Liber Extra nennt als Voraussetzungen, die eine dem Original gegenüber gleichwertige Abschrift erfüllen muss: die begründete Bitte um Transsumierung, die Vorlage des Originals vor einem ordentlichen oder delegierten Richter, die genaue Untersuchung desselben, die Feststellung der Unverfälschtheit sowie die Anfertigung der Abschrift durch einen öffentlichen Notar (X 2.22.16: Si instrumenta propter vetustatem vel propter aliam iustam causam exemplari petantur, coram ordinario iudice vel delegato ab eo specialiter praesententur. Qui si ea diligenter inspecta in nulla sui parte vitiata repererit, per publicam personam illa praecipiat exemplari, eandem auctoritatem per hoc cum originalibus habitura $)^{32}$.

Aus dieser Norm wird abgeleitet, dass ein Notar allein keine voll beweiskräftige Abschrift anfertigen könne, da er lediglich die Übereinstimmung von Abschrift und Urschrift, nicht aber die Echtheit der letzteren feststellen könne. Die Urteilskraft, ob das

27 Z. B. BayHStA München, Kloster Altenhohenau Urk. 1425 IV 2: propter viarum discrimina et variorum periculorum eventus via ignis, voraginis, mundacionis, aquarum et aliorum timentes.

28 HHStA Wien, AUR 1318 XII 5. Zum Begriff fides vgl. Schulte, Petra: „Scripturae publicae ceditur“. Das Vertrauen in Notariatsurkunden im kommunalen Italien des 12. und 13. Jahrhunderts. Tübingen 2003, S. 4-12.

29 Bresslau, H.: Handbuch der Urkundenlehre, S. 92; ähnliche Einschätzungen bei Paarhammer, Hans: Rechtsprechung und Verwaltung des Salzburger Offizialates (1300-1569). Dissertationen der Universität Salzburg 8. Wien 1977, S. 165.

30 Vgl. Oesterley, Ferdinand: Das deutsche Notariat nach den Bestimmungen des gemeinen Rechts und mit besonderer Berücksichtigung der in den deutschen Bundesstaaten geltenden particularrechtlichen Vorschriften. Erster Theil: Geschichte des Notariats. Hannover 1842, S. 335 und Zweiter Theil: Darstellung des geltenden Rechts. Hannover 1845, S. 489-503; Trusen, Winfried: Zur Urkundenlehre der mittelalterlichen Jurisprudenz. In: Recht und Schrift im Mittelalter. Hg. von P. Classen. Vorträge und Forschungen 23. Sigmaringen 1977, S. 197-219, hier: S. 214; Ders.: Das Notariat und die Anfänge der rechtlichen Urkundenlehre in Deutschland. Deutsche Notar-Zeitschrift 13, 1986, S. 13-24, hier: S. 20; Schulte, P.: Scripturae publicae, S. 182.

31 Vgl. Trusen, W.: Urkundenlehre, S. 205.

32 Corpus iuris canonici. Hg. von E. Friedberg. Graz 1959 (unveränderter Neudruck der Ausgabe Leipzig 1879), S. 353. 
Original nicht nur unbeschädigt, sondern auch in anderer Hinsicht unverdächtig ist, komme grundsätzlich nur einem Richter zu. Dies wird auch im Speculum iudiciale, das als "Standardwerk der mittelalterlichen Prozessrechtswissenschaft" ${ }^{33}$ gilt, deutlich. So beschreibt Durantis unter dem Titulus De instrumentorum editione im zweiten Buch des Speculum unter Rückgriff auf die Summa artis notariae des Bologneser Notariatslehrers Rolandinus $^{34}$ verschiedene Möglichkeiten zur Anfertigung von Abschriften (exempla) und unterscheidet dabei zwischen Kopien, die nur der Erinnerung dienen (ad solam memoriam) und solchen, die vor Gericht voll beweiskräftig sein sollen (ut plena fides adhibeatur). Verschiedene Vorgehensweisen werden erklärt und durch Musterformulare illustriert. Die erste Variante ist die Abschrift, die nur von einem oder mehreren Notaren (in der Form des unbesiegelten Notariatsinstruments) beglaubigt wird. Zu diesen schreibt Durantis ausdrücklich: non praebent exemplo plenam fidem [...], licet ad solam memoriam fiat. ${ }^{35}$ Damit eine Abschrift dem Original gleichwertig und voll beweiskräftig ist, gibt es verschiedene Möglichkeit: Entweder wird eine bereits angefertigte Abschrift nachträglich vom Richter überprüft, mit dem Original abgeglichen und beglaubigt, oder der Richter erteilt dem Notar den Auftrag zum Abschreiben erst, nachdem er die Unverdächtigkeit des vorgelegten Stückes festgestellt hat. Das Transsumpt ist dann nicht nur vom Notar, sondern auch vom Richter zu unterschreiben - eine Art der Beglaubigung, die in Bayern und Österreich allerdings nicht üblich scheint.

Daneben beschreibt Durantis jedoch noch eine Variante, in der die Abschrift ihre Glaubwürdigkeit (auctoritas) durch das Siegel eines Bischofs oder einer anderen „glaubwürdigen Person“ (persona authentica) erhält - worunter wahrscheinlich jemand aus dem nicht genau umrissenen Kreis von Personen gemeint ist, deren Siegel als sigilla authentica gelten. ${ }^{36}$ Anscheinend wird also auch diesen die Autorität zugestanden, die Unver-

33 Lepsius, Susanne: Art. Durantis, Guilelmus (um 1230-1296). HRG 12, Sp. 1168-1170.

34 Durantis greift insbesondere auf Teile von c. 10 De exemplificatione der Summa Rolandina zurück: Summa artis notariae D. Rolandini Rodolphini Bononiensis [...] (= Summa Rolandina). Speyer 1590, S. 714-723. Digitalisat des Exemplars in der Bayerischen Staatsbibliothek München (= BSB), J.pract. 260a: http://www. mdz-nbn-resolving.de/urn/resolver.pl?urn=urn:nbn:de:bvb:12-bsb10181607-6 (15. 5. 2017).

35 Auch wenn der Notar das Fehlen von cancellationes vel interlineaturas konstatiere, wären doch noch andere glaubwürdigkeitsrelevante Mängel möglich, etwa in der Person des Notars oder dessen Auftraggebers, für die dem Notar nicht die notwendige Urteilskraft zukommt: D. G. Durandi Episc. Mimatensis Speculum iuris cum Ioan. Andreae, Baldi, reliquirumque clarissimorum i. v. doctorum visionibus hactenus addi solitis. Pars secun$d a$ (= Dur. II). Frankfurt [am Main] 1592. Digitalisat des Exemplars der BSB, 2 J.pract. 38-1/4\#2: http:// daten.digitale-sammlungen.de/ $\sim \mathrm{db} / 0008 /$ bsb00087947/images (15. 5. 2017), S. 287 (Tit. De instrumentorum editione, $\S 4$ Ostenso qualiter) n. 5: Unde si tabellio exemplans publicum instrumentum, dicit se scripsisse, prout in authentico continebatur, nec plus, vel minus; nec in eo interfuisse, vel insertas fuisse aliquas cancellationes, vel interlineaturas, non probatur per tale publicum exemplum; tum, quia non est officium notarii firmare primum instrumentum authenticum, et ei firmitatem praestare; tum, quia licet ita scripserit, prout in primo continebatur, nec sint ibi cancellationes vel interlineaturae, tamen possunt ibi esse alia, propter quae fides illi [non] adhibetur, vel propter personam tabellionis, vel propter personam eius, qui illud confici fecit. [Ergänzung des fehlerhaften Drucks nach der Ausgabe Padua 1479, Digitalisat des Exemplars der BSB, 2 Inc. c. a. 843-2: http://daten. digitale-sammlungen.de/ $\sim \mathrm{db} / 0006 /$ bsb00066674/images (15. 5. 2017)].

36 Dur. II, S. 288 (Tit. De instrumentorum editione, $\$ 4$ Ostenso qualiter) n. 11: Hoc autem scias, quod plerumque adhibetur auctoritas episcopi vel alterius authenticae personae, praesertim in exemplis literarum, quae quidem in testimonium et fidem ipsius exempli faciet illud suo sigillo muniri. Vgl. Summa Rolandina, S. 716. 
dächtigkeit einer Urkunde festzustellen. Dass diese exempla zusätzlich zu der Besiegelung auch durch einen öffentlichen Notar zu beglaubigen sind, erwähnt Durantis zwar nicht ausdrücklich, dies wird jedoch durch die für diese Variante angebotenen Musterformulare verdeutlicht. Man kann wahrscheinlich davon ausgehen, dass auch die Aussteller der notariellen Siegelurkunden, die in bayerischen und österreichischen Archivbeständen überliefert sind, größtenteils als personae authenticae galten.

Schließlich erläutert Durantis, nun unter Rückgriff auf die Summa aurea des Heinricus de Segusio, genannt Hostiensis, noch ein gerichtliches Beglaubigungsverfahren, das als publicatio bezeichnet wird. Die Parallelen zu dem oben erwähnten Verfahren, das in 42 der besiegelten Transsumpten geschildert wird, sind deutlich: Die Abschrift wird erst nach einer Ladung etwaiger Betroffener und der richterlichen Feststellung der Echtheit des vorgelegten Stückes vom Notar ausgefertigt und beglaubigt, sowie mit dem Siegel des Richters versehen. Hatte Hostiensis das Publikationsverfahren vor allem im Zusammenhang mit der Veröffentlichung von Zeugenaussagen oder der Testamentseröffnung beschrieben, ${ }^{37}$ setzt es Durantis im Speculum in den Kontext der Beglaubigung von Abschriften. Gegenüber der zuvor beschriebenen Vorgehensweise sei die publicatio insbesondere dann notwendig, wenn man aufgrund von Beschädigungen durch Alter, Brand oder auch Mäusefraß den Verlust eines Privilegs oder eines Instruments befürchte, oder auch, wenn die darin beurkundeten Vorgänge geleugnet würden ${ }^{38}$. Mittels publicatio hätte man demnach ein glaubwürdiges Transsumpt auch in jenen Fällen erlangt, in denen das Original anfechtbar erscheint. Dieses aufwändige gerichtliche Transsumierungsverfahren dient also nicht nur der Beglaubigung der Abschrift, sondern vor allem auch der Feststellung der Echtheit der Vorlage.

Zwischen den drei verschiedenen Arten notariell beglaubigter Transsumpte in den bayerischen und österreichischen Urkundenbeständen und drei der im Speculum iudicia$l e$ beschriebenen Verfahren sind also deutliche Parallelen festzustellen. $\mathrm{Ob}$ man deshalb Durantis' Aussagen zur Beweiskraft der verschiedentlich beglaubigten Abschriften auf die drei in Bayern und Österreich überlieferten Arten notarieller Transsumpte übertragen kann, bleibt allerdings unklar. Die wenigen bekannten Gerichtsprozesse im 14. und 15. Jahrhundert, in denen Abschriften als Beweismittel eine Rolle spielen sollten, vermitteln kein klares Bild. ${ }^{39}$ Zudem sind, vergleicht man die inserierten Urkunden

37 Heinrico de Segusio Cardinalis Hostiensis, Summa aurea. Ad vetustissimos codices summa fide diligentiaque nunc primum collata [...]. Basel 1573, hier: Sp. 524-527 (Tit. De Fide instrumentorum), n. 10-12. Digitalisat des Exemplars der BSB, 2 J.can. u. 92: http://reader.digitale-sammlungen.de/resolve/display/bsb10144629. html (15. 5. 2017).

38 Dur. II, S. 291 n. 25: In quibus casibus locum habeat, facile est videre: [...] Item in privilegiis et instrumentis, quando propter vetustatem vel aliam iustam caussam timetur de consumptione ipsorum, puta, quia litera incipit deleri propter chartae vitium vel encausti [...], vel a muribus corrodi; S. 292 n. 31: Et (ut hec plenius intelligas) nota, quod quandoque petuntur attestationes vel alia publicari; puta, quia scriptae sunt per solum tabellionem sine testium subscriptione; nec inveniuntur apud iudicem authenticatae per tabellionem; vel forte negantur esse acta: tunc enim est publicatio necessaria et non aliter.

39 In den bei Frenz, Thomas: Die angeblichen Gründungsprivilegien des Klosters Kempten und ihre Rolle im Streit zwischen Stift und Reichsstadt Kempten. Ein Beispiel spätmittelalterlicher Urkundenkritik. In: Fälschungen im Mittelalter. Internationaler Kongreß der Monumenta Germaniae Historica, München 16.-19. Sept. 1896. Hg. von D. Jasper, Hannover 1988, S. 611-624, hier: S. 619f. und Märtl, Claudia: Isto anno prevalebunt 
miteinander, keine gesetzmäßigen Zusammenhänge zwischen Beglaubigungsverfahren und Aussteller, Alter und Inhalt der abgeschriebenen Urkunde festzustellen, etwa dass Kaiser- und Papsturkunden aufwändigere Verfahren erfordert hätten als andere oder dass ältere oder besonders bedeutende Schriftstücke nicht auch in der einfacheren Form des unbesiegelten Notariatsinstruments transsumiert worden wären. Man kann zwar durchaus davon ausgehen, dass ein Petent die publicatio einer zu transsumierenden Urkunde nur dann anstrebte, wenn er mit Widerspruch gegen das (vermeintliche) Original rechnete; die gar nicht so seltenen Fälle, in denen Fälschungen notariell transsumiert wurden, ${ }^{40}$ zeigen indes, dass der Umkehrschluss nicht zulässig ist: Auch wenn eine Urkunde aufgrund von Rasuren oder interlinearen Ergänzungen erheblichen Anlass zu Zweifeln gab, gab es nicht immer ein solches Verfahren.

Die hypothetische Frage, ob eine notariell beglaubigte Abschrift von einem geistlichen Richter als Beweismittel anerkannt worden wäre, oder ob er auf Beibringung des Originals, weiterer Urkunden oder Zeugen bestanden hätte, ist letztlich nur ein Aspekt, der für die Zeitgenossen nicht immer im Vordergrund stand. Schließlich ist zwischen „Beweiskraft“ und „Glaubwürdigkeit“ zu unterscheiden. Hielt derjenige, dem man ein Transsumpt vorlegte, Form und Inhalt für glaubwürdig, auch wenn er seine eigenen Rechte dadurch eingeschränkt sah, dann war unbedeutend, was ein Richter darüber geurteilt hätte. Potenzielle Gegenparteien mussten zudem damit rechnen, dass es noch andere Beweise, oft sogar das sicher verwahrte Original gab. ${ }^{41}$ In anderen Fällen war von vornherein nicht davon auszugehen, dass jemand den Inhalt der inserierten Urkunde vor Gericht bestreiten würde, beispielsweise bei Ablassbriefen. ${ }^{42}$ Manchmal stand hinter der Anfertigung einer beglaubigten Abschrift vielleicht auch der Wunsch nach

falsarii. Fälscher im spätmittelalterlichen Regensburg. Ebd., S. 551-571, hier: S. 556f. erwähnten Fällen aus dem wurde zwar die Tatsache, dass es sich um Abschriften handelt, thematisiert, nicht aber, ob und wie diese beglaubigt waren. Die z. B. bei Foerster, Hans: Beispiele mittelalterlicher Urkundenkritik. Archivalische Zeitschrift (= AZ) 50/51, 1955, S. 301-318 und Klein, Herbert: Ein Salzburger Prozeß von 1423 um eine niederbayerische Urkundenfälschung. AZ 56, 1960, S. 76-83 beschriebenen Beispiele mittelalterlicher Urkundenkritik beziehen sich nicht auf Transsumpte.

40 Z. B. BayHStA München, Hochstift Passau Urk. 1167 (1408 September 2) mit Insert eines gefälschten Diploms Kaiser Arnulfs von 898 September 9 (ebd., Hochstift Passau Urk. 11; MGH DD III. Arnolfi diplomata. Hg. von P. Kehr. Berlin 1940, S. 247-250, Nr. 163); BayHStA München, Kloster Formbach Urk. 56, mit Insert einer gefälschten Urkunde Lothars III. (ebd., Kloster Formbach Urk. 4; J. F. Böhmer, Regesta Imperii. IV. Lothar III. und ältere Staufer. Abt. 1: Die Regesten des Kaiserreiches unter Lothar III. und Konrad III. Tl. 1: Lothar III 1125 (1075)-1137. Neuberabeitet von Wolfgang Petke. Köln - Weimar - Wien 1994, S. 305f. Nr. †480); BayHStA München, Kloster Raitenhaslach Urk. 1470 V 18/1 mit Insert einer gefälschten Papsturkunde (ebd., Raitenhaslach Urk. 1147 I 28). Vgl. auch Härtel, Reinhard: Fälschungen im Mittelalter: geglaubt, verworfen, vertuscht. In: Fälschungen im Mittelalter. Internationaler Kongreß der Monumenta Germaniae Historica, München 16.-19. Sept. 1896. Hg. von D. Jasper, Hannover 1988, S. 29-51, hier: S. 39-50; Zajic, Andreas H. - Roland, Martin: Eine spätmittelalterliche Urkundenfälschung aus dem Augustiner-Chorherrenstift Dürnstein in Niederösterreich. Zugleich ein Beitrag zu illuminierten Urkunden des Mittelalters. AfD 51, 2005, S. 331-432.

41 Bei mindestens einem Drittel der 289 dieser Studie zugrundeliegenden Transsumpte ist das inserierte Stück noch im Original im jeweils gleichen Urkundenbestand erhalten.

42 Vgl. drei Transsumpte des Ablasses Papst Bonifaz' IX. vom 4. Mai 1400 (vgl. Krausen, Edgar: Regesten der Urkunden des Zisterzienserklosters Raitenhaslach 1351-1803. Burghausen 1989, S. 38 Nr. 82): BayHStA München, Kloster Raitenhaslach Urk. 1401 I 13, 1401 III 18 und 1443 IV 15. 
optischer Aufwertung, schließlich konnte eine Notarsurkunde allein durch das Signet grafisch ansprechend sein. Andreas Zajic hat auf Beispiele reich illuminierter notarieller Transsumpte aufmerksam gemacht, ${ }^{43}$ bei denen die Frage nach der gerichtlichen Beweiskraft nach gelehrtem Prozessrecht allenfalls sekundär war.

Es ist festzuhalten, dass Transsumpte in Form der notariellen Siegelurkunde sehr häufig überliefert sind und offenbar den Regelfall der beglaubigten Abschrift für geistliche Empfänger darstellten. Sie galten nicht nur nach römisch-kanonischem Prozessrecht als voll beweiskräftig, indem eine persona authentica die Unversehrtheit und Unverdächtigkeit der Vorlage bestätigte, sondern offenbar auch in der Praxis als glaubwürdig. Auch wenn gerichtliche Beweiskraft nicht notwendig schien, wählte man häufig diese Form, sei es aus Vorsicht oder aus Gewohnheit. Spätestens seit den 1430er Jahren sah man in Bayern und Österreich gelegentlich Anlass dafür, vor der Transsumierung eine richterliche publicatio der Urkunde vornehmen zu lassen, von der man eine beglaubigte Abschrift wünschte. In anderen Fällen wiederum verzichtete man auf die Hinzuziehung eines Richters oder einer persona authentica, auch wenn die Beweiskraft der Abschrift dadurch eingeschränkt erscheint.

Sicher stand hinter einer bestimmten Form nicht immer eine bewusste Entscheidung in Kenntnis prozessrechtlicher Normen, wie sie bei Durantis dargelegt sind, und so lässt sich auch aus der spezifischen Form eines notariell beglaubigten Transsumpts nicht grundsätzlich auf einen bestimmten Zweck dieser Abschrift schließen. Inhalt und Überlieferungskontext einzelner Transsumpte müssen daher stets in die Untersuchung mit einbezogen werden. Dann aber liefert nicht zuletzt die Form wichtige Hinweise darauf, ob die Abschrift ad solam memoriam angefertigt wurde, oder ut plena fides adhibeatur und damit für die Verortung sowohl der Abschrift als auch ihrer Vorlage als Urkunden „zwischen Recht und Erinnerung“.

\section{Ad solam memoriam nebo ut plena fides adhibeatur? K notářsky ověřeným transsumptům z bavorských a rakouských fondů.}

Příspěvek se věnuje notářsky ověřeným opisům ze 14. a 15. století uloženým ve vybraných bavorských a rakouských fondech, zejména pak jejich průkaznosti z pohledu římsko-kanonického procesního práva. Nejprve jsou vysvětleny příčiny terminologických nedorozumění v německé odborné literatuře. Zatímco soudobé prameny označují opisy pořízené veřejnými notáři a opatřené jejich znamením a podpisem jako transsumpta, tento výraz má (zřejmě nedopatřením) v německých syntézách a terminologických slovnících zcela jiný význam - znamená totiž listiny, v nichž právní nástupci původních vydavatelů formou insertů potvrzují nějaké starší listiny, a to včetně jejich obsahově právní podstaty. Na základě cca 300 listin jsou popsány hlavní znaky notářských transsumptů a jsou stanoveny jejich tři typy. Ty se mezi sebou navzájem odlišují zejména tím, zdali u nich po běžném notářském ověření následovalo ještě zpečetění, a dále tím, jak nákladná

43 Vgl. Zajic, A. H. - Roland, M.: Urkundenfälschung; sowie die von Andreas Zajic mitgeteilten Beispiele bei: De Hamel, Christopher - Bergeron-Foote, Ariane: Diplomatics. Primer 7. New York - Chicago - Paris 2015, S. 12f. Nr. 4 und S. 20f. Nr. 8. 
byla v textu zvolená forma notářského ověření. Z 30. let 15. století jsou dochovány zpečetěné transsumpty, v nichž se popisují právní úkony, které ověření dotyčného opisu předcházely. Výše nákladů spojených s ověřováním opisů odpovídala zajisté různým stupňům jejich průkaznosti. Zatímco odborná literatura někdy považuje notářsky ověřené opisy za stejně průkazné jako originály, papežské dekretály a soudobá legistická literatura zaměřená na procesně právní aspekty poskytuje odlišný obrázek: podle těchto textů totiž nemají opisy ověřené at již jen jedním nebo více veřejnými notáři plnou průkaznost. Aby se plně průkaznými staly, musela být splněna ještě některá další kritéria. Př́íspěvek se na tato kritéria zaměřuje a dále rovněž na skutečnost, nakolik byly pro práci veřejných notářů činných v Bavorsku a Rakousích závazné zásady římsko-kanonického procesu. 